\title{
Relation between private health insurance and high rates of caesarean section in Chile: qualitative and quantitative study
}

Susan F Murray

\begin{abstract}
Objectives To explore the circumstances and factors that explain the association between private health insurance cover and a high rate of caesarean sections in Chile.

Design Qualitative analysis of audiotaped in-depth interviews with obstetricians and pregnant women; quantitative analysis of data from face to face semistructured interview survey conducted postnatally (with women who had given birth in the previous 24-72 hours), and of a review of medical notes at a public hospital, a university hospital, and a private clinic.

Setting Santiago, Chile.

Participants Qualitative arm: 22 obstetricians, 21 pregnant women; quantitative arm: 540 postnatal women.
\end{abstract}

Main outcome measures Rates of caesarean section in different types of institutions; consultants' views on private practice; work patterns in private practice; women's reasons for choosing private care; women's preferences on method of delivery.

Results Private health insurance cover requires the primary maternity care provider to be an obstetrician. In the postnatal survey, women with private obstetricians showed consistently higher rates of caesarean section (range 57-83\%) than those cared for by midwives or doctors on duty in public or university hospitals (range 27-28\%). Only a minority of women receiving private care reported that they had wanted this method of delivery (range 6-32\%). With the diversification in the healthcare market, most obstetricians now have demanding peripatetic work schedules. Private maternity patients are a lucrative source of income. The obstetrician is committed to attend these private births in person, and the "programming" (or scheduling) of births is a common time management strategy. The rate of elective caesarean sections was $30-68 \%$ in women with private obstetricians and 12-14\% in women not attended by private obstetricians.

Conclusions Policies on healthcare financing can influence maternity care management and outcomes in unforeseen ways. The prevailing business ethos in health care encourages such pragmatism among those doctors who do not have a moral objection to non-medical caesarean section.

\section{Introduction}

An ecological study of rates of caesarean sections in Latin America reported that 12 countries, accounting for $81 \%$ of births in the region, had caesarean rates of over $15 \%$, the upper limit recommended by the World Health Organization. ${ }^{1}$ Chile had the highest rate- $40 \%$ in 1997. In Chile, the rate of caesarean sections in women with private health insurance is double that in women covered by the national health insurance fund. ${ }^{2}$

Until the 1980s all salaried workers in Chile subscribed to a unified national health fund. With government encouragement, private health insurance funds were launched in $1981 .^{3}$ By 1994 a quarter of healthcare users had joined such a fund. ${ }^{2}$

Type of insurance cover has important implications for the type of maternity care received. In Chile's public healthcare system (funded through the national health insurance fund) women receive antenatal and postnatal care at the local health centre, and intrapartum care at the local hospital. Much of that care is provided by professional midwives. Private health insurance, on the other hand, normally requires the primary care provider to be an obstetrician.

I carried out a study of the day to day organisation, norms, and relationships in private sector maternity care in Santiago, Chile's capital city, to examine why private health insurance is associated with high rates of caesarean section.

\section{Participants and methods}

I obtained approval for the study from Chile's health ministry. Data were collected between 1995 and 1997, in Santiago, where a third of the country's population lives. As Chile had no tradition of large scale postal questionnaires, a face to face interview survey of postnatal women (women who had given birth in the previous 24-72 hours), plus a review of medical records, was used to provide quantifiable data on aspects of care management and women's experiences of labour care. Qualitative data from the analysis of in-depth audiotaped interviews with obstetricians and pregnant women were used to develop an understanding of the day to day influences on birth management in the private sector and to derive inferences about underlying belief systems that drive professional behaviour in this setting.

\section{Participants}

\section{Quantitative arm}

Three sites were chosen to reflect the range of maternity care in Santiago (table 1). Agreement to take part in the study was obtained from each site's director. The private sector was the most difficult site to gain access to, but the fourth private clinic approached agreed to participate. All women with live births during two 14 day periods were approached for interview, except at the public hospital, where consecutive "time of birth" sampling of every third woman was used to maintain a manageable number of interviews daily. This sampling was continuous through all shifts for each fortnight, and the statistics for method of delivery for this subset tally well with the hospital's annual statistics.

\section{Centre for \\ International Child \\ Health, Institute of \\ Child Health, \\ University College \\ London, London \\ WC1N 1EH \\ Susan F Murray \\ lecturer \\ s.murray@ich.ucl.ac.uk}

BMJ 2000;321:1501-5

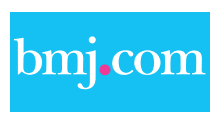

Two tables with data on the characteristics of participating obstetricians and pregnant women appear on the BMJ's website 
Table 1 Characteristics of the three hospital sites in Santiago used in postnatal survey and for review of medical records, plus sampling method used

\begin{tabular}{|c|c|c|}
\hline Site & $\begin{array}{l}\text { No of births per year } \\
\text { (\% that are caesarean) }\end{array}$ & Sampling method (with stillbirths excluded) \\
\hline University hospital (one of two) & $2600(36)$ & $\begin{array}{l}\text { Every woman who gave birth attended by member of on-duty } \\
\text { hospital staff, during two } 14 \text { day periods }(n=106) \text {; every woman } \\
\text { who gave birth attended by their private obstetrician in university } \\
\text { hospital site during same two } 14 \text { day periods ( } n=63 \text { ) }\end{array}$ \\
\hline
\end{tabular}

All women invited for interview $(\mathrm{n}=540)$ agreed to take part and were interviewed. Case notes for all respondents were reviewed. Missing data were recorded. Monthly birth statistics for the preceding year were subjected to the $\chi^{2}$ goodness of fit test. This confirmed that the survey periods were unlikely to be atypical of the rest of the year.

\section{Qualitative arm}

Twenty three obstetricians were invited to participate; an opportunistic maximum variation sampling approach was used to ensure an extensive range of demographic characteristics, experiences, work contexts, and attitudes to caesarean section (see table A on the $B M /$ s website). One senior doctor declined to take part. None of the 22 who agreed to participate refused audiotaping of the interview. Only one female obstetrician took part, reflecting male dominance in the profession in Chile.

Twenty one pregnant women were recruited (none of those invited refused) by using the same sampling method to ensure a range of socioeconomic status, age, and parity (see table $\mathrm{B}$ on the $B M J$ s website). They had been contacted through social networks and through healthcare providers. None refused audiotaping of the interview.

\section{Methods}

Quantitative interviews took place in postnatal rooms 24-72 hours after delivery. A semistructured questionnaire (previously piloted in these settings) about women's expectations and experiences of childbirth was administered by an experienced local social scientist.

Qualitative interviews, lasting 40 minutes to two hours, took place in obstetricians' consulting rooms or at interviewees' homes. I conducted these interviews in Spanish using a series of structured prompting questions covering the areas of interest. The audiotaped and transcribed interviews were anonymous. Transcription was done by six native speakers of Spanish and was checked against the recordings by the interviewer to ensure accuracy.

\section{Analysis}

Data collected from the survey and the review of medical records were entered on SPSS for Windows. The transcripts of the in-depth interviews were analysed by using QSR NUD*IST software to facilitate cross indexing. The entire Spanish text was entered. I carried out the coding and analysis. I examined the transcripts closely for emerging themes and coded the blocks of text into nine broad categories of statement generated from the data (see below). I examined the qualitative data for examples of "negative instances" that might contradict these emerging themes, explored the reasons for these, and modified my interpretation accordingly. I used survey data and other institutional statistics to test the qualitative conclusions and to examine possible counter-explanations.

\section{Results}

\section{Obstetricians}

Private obstetrician care was consistently associated with higher rates of caesarean section in the subpopulations of the postnatal women surveyed (difference in percentages was $55 \%$ (95\% confidence interval $42 \%$ to $68 \%)$ for women in the public hospital and 30\% (15\% to $45 \%$ ) for women in the university hospital) (table 2).

\section{Reasons for doing private practice}

Private sector work was seen as a necessary element of income generation. The balance and type of work might vary, but even trainee specialists had private practices.

All 22 obstetricians reported that the principal motivation of obstetricians for doing private maternity work was financial. A university hospital doctor said his monthly salary (about $£ 700 ; \$ 1000$ ) could be matched by the income from providing care to one private patient. As many private patients arrived by personal recommendation, volume was a measure of professional success. For anyone aspiring to work in an exclusive private clinic, proof of ability to generate substantial numbers of patients was important. A few

Table 2 Type of delivery, by institution and provider of care, according to data collected in postnatal survey. Values are numbers of deliveries (percentage of total)

\begin{tabular}{|c|c|c|c|c|c|}
\hline \multirow[b]{2}{*}{ Delivery } & \multicolumn{2}{|c|}{ Public hospital } & \multicolumn{2}{|c|}{ University hospital } & \multirow[b]{2}{*}{$\begin{array}{l}\text { Women attended by } \\
\text { private obstetrician, } \\
\text { private clinic }(n=177)\end{array}$} \\
\hline & $\begin{array}{l}\text { Women attended by } \\
\text { midwife or doctor on } \\
\text { duty }(n=147)\end{array}$ & $\begin{array}{c}\text { Women attended by } \\
\text { private obstetrician } \\
(\mathrm{n}=47)\end{array}$ & $\begin{array}{l}\text { Women attended by } \\
\text { midwife or doctor on } \\
\text { duty }(\mathrm{n}=106)\end{array}$ & $\begin{array}{l}\text { Women attended by a } \\
\text { private obstetrician } \\
(n=63)\end{array}$ & \\
\hline Caesarean section & $41(28)$ & $39(83)$ & $29(27)$ & $36(57)$ & $123(69)$ \\
\hline Unassisted vaginal delivery & $104(71)$ & $7(15)$ & $62(58)$ & $25(40)$ & $45(25)$ \\
\hline Forceps delivery & $2(1)$ & $1(2)$ & $15(14)$ & $2(3)$ & $9(5)$ \\
\hline
\end{tabular}

Percentages may not total 100 owing to rounding. 
obstetricians mentioned continuity of care and long term relationships as positive features of private work. Those working in elite private hospitals said they could offer superior care because of better resources.

\section{Work patterns in private practice}

Most obstetricians had private maternity patients, who were viewed as the most lucrative but most demanding part of private work. With the growth in private insurance, and consequent increased opportunities, private maternity facilities in Santiago have mushroomed, and obstetricians can bring their patients to most of these for labour care or operations. Public and teaching hospitals also have facilities for private patients. But, although the obstetrician may state his or her preference, the private patient chooses the facility. All but the most favoured obstetricians have to be mobile, and have work commitments in several scattered locations.

Some obstetricians leave public or university jobs to work freelance, or, if highly successful and well connected, to join an exclusive private clinic. Leaving behind a secure post was considered risky: "It is just like a business, a shop.... The day that you don't hold a surgery you simply don't earn any money...." (Obstetrician 19)

Problems generated by private maternity work Many of the obstetricians felt vulnerable to the market nature of their private work. They felt competitive pressures and a need to keep patients happy. They also recognised women's expectations of personal care: "I have to make the patient feel, once she is coming to me for antenatal care, that I am permanently at her disposal, for whatever emergency, whatever the hour, whatever the day." (Obstetrician 1)

This commitment to availability is an organisational challenge, given fixed commitments such as consulting hours, hospital rounds, and sessional bookings. Trips away can be difficult. Most doctors needed to seek equilibrium between the demands of private work, the requirements of their "base" job, and their personal life.

\section{Strategies for dealing with complex work patterns}

Obstetricians reconciled the conflicting demands by $(a)$ opting out of private obstetric practice (although few felt they could afford to do this); (b) limiting the number of private patients by increasing fees, accepting only early bookings, or limiting appointments; (c) centralising work over fewer locations (or joining an exclusive private hospital and working only there); or (d) "programming" (or scheduling) births (box).

One method of programming is induction of labour once the cervix is deemed ripe and the fetus suitably mature, at a time that suits all parties. Although induction of labour can often probably be organised quite effectively in this way, some inductions do fail and result in caesarean section.

Early labour care is provided by a midwife employed by the obstetrician, who keeps the obstetrician informed by telephone so that he or she and the paediatrician can arrive at the right time. The alternative programming method-elective caesarean section-is more reliable and demands a shorter time

\section{Programming (or scheduling) births*}

Interviewer: "So you finish your day at about $8.30 \mathrm{pm}$ more or less?"

Obstetrician: "No, no then come the operations .. Our specialty has a high number of patients who have surgery or some intervention... You try to place the delivery care in this timetable in the evening-that is to say, a programmed birth. As I know my patient, I try to see to it that she has the birth to more or less fit in, that she has it on the day that I have specifically allocated, and generally it is at this hour. Apart from, exceptionally, the ones who give birth when their moment arrives-those patients who get you out of the hospital or the consulting rooms or the house at night or who get you out at the weekend. But in general, after so many years in the specialty, you arrange things to a programme a little, to direct the birth towards a timetable that suits you."

*From audiotaped interview with obstetrician 14

commitment, and because of this is more financially rewarding. Elective caesarean section is more common among patients attended by private obstetricians (difference in percentages was $56 \%$ (95\% confidence interval $41 \%$ to $70 \%$ ) for women in the public hospital and $16 \%$ (3\% to $29 \%)$ for women in the university hospital) (table 3).

\section{Attitudes to rates of caesarean section}

The obstetricians interviewed knew that rates of caesarean section were higher in much of the private sector and that the issue of a "correct" rate was controversial; some suggested two schools of obstetrician"vaginalists" and "operators" (or "caesareanists"). Vaginalists took more overtly advocatory positions and voiced moral and ethical concerns over non-medical caesarean sections.

Those unconcerned about the current rates of caesarean section said that the procedure under epidural was safe and relatively simple and therefore unproblematic. Some obstetricians admitted that on occasion they agreed to a patient's request for a caesarean section in order not to lose her custom to another doctor.

\section{Women}

\section{Views on private maternity care}

Most women with private obstetricians chose their doctor through recommendation of a friend or relative (64\% of the survey participants from the private clinic; $80 \%$ from the public and university hospitals). Table 4 shows the reasons for consulting privately.

Table 3 Rates of elective caesarean sections, by institution and provider of care, according to review of medical notes

\begin{tabular}{lc} 
Institution and care provider & $\begin{array}{c}\text { No of elective caesareans/ } \\
\text { total No of deliveries (\%) }\end{array}$ \\
\hline Public hospital: & \\
\hline Midwife or doctor on duty & $18 / 147(12)$ \\
\hline Private obstetrician & $32 / 47(68)$ \\
\hline University hospital: & $15 / 106(14)$ \\
\hline Midwife or doctor on duty & $19 / 63(30)$ \\
\hline Private obstetrician & $88 / 177(50)$ \\
\hline Private clinic &
\end{tabular}


Table 4 Principal reason for consulting private obstetrician, according to postnatal survey. Values are numbers (percentages) of women

\begin{tabular}{lccc} 
Reason & $\begin{array}{c}\text { Public hospital with } \\
\text { private obstetrician } \\
(\mathbf{n = 4 7 )}\end{array}$ & $\begin{array}{c}\text { University hospital } \\
\text { with private } \\
\text { obstetrician }(\mathbf{n = 6 3 )}\end{array}$ & $\begin{array}{c}\text { Private clinic with } \\
\text { private obstetrician } \\
(\mathbf{n = 1 7 7})\end{array}$ \\
\hline Clinical care is better & $21(45)$ & $30(48)$ & $63(36)$ \\
\hline Personal care is better & $8(17)$ & $13(21)$ & $58(33)$ \\
\hline Condition of health insurance & $17(36)$ & $11(17)$ & $48(27)$ \\
\hline Other reasons & $1(2)$ & $8(13)$ & $8(5)$ \\
\hline Missing data & 0 & $1(2)$ & 0 \\
\hline
\end{tabular}

Percentages may not total 100 owing to rounding.

In the qualitative interviews, although some had unsatisfactory previous experiences, all 12 women with private obstetricians were enthusiastic about them. The personalised nature of the doctor-patient relationship was important to them (box). They described "empathy," "chemistry," and "humane qualities," "being on the same wavelength," and "speaking the same language" as their obstetricians, whom they referred to by first name.

\section{Preferences for method of delivery}

The postnatal women were asked if at any point in their pregnancy they had wanted a caesarean section. Some reported that they had (range $6-32 \%$ of those receiving private care from obstetricians). At the private clinic, where $70 \%$ of the women surveyed had had a caesarean section, only $18 \%$ said that they had wanted one.

\section{Discussion}

In Brazil the absence of insurance cover for tubal ligation resulted in caesarean section being used as an opportunity for clandestine tubal ligation. ${ }^{5}$ In Chile, policies on healthcare financing have also influenced the management of maternity care and outcomes in unforeseen ways. Private health insurance cover in Chile normally requires the primary provider of maternity care to be an obstetrician, and women with private obstetricians showed consistently higher rates

\section{Expectation of personal commitment in a} private care relationship*

"I have all my doctor's phone numbers, and the midwife's - the mobiles, the bleeper, and all those things. I know I can call Carlos at three in the morning, that I can call him at any hour. I know that." (Woman 9, fourth pregnancy)

"I like him to do my scans, my own doctor. Not that he sends me to someone else, but that he himself does the scans. I like the fact that he makes me go [for a scan] once a month. I think all these things show concern, and I like that-it makes me feel secure."(Woman 14, second pregnancy)

"There is no alternative. I'd die. No, no, no, I can't think anything else is possible. My doctor is going to get my baby born - that's super clear.... He can't be away when there is a birth. He has made a commitment, he knows that..." (Woman 15, first pregnancy)

"I've never asked Claudio if he is or is not going to be there- that is to say, I don't have the least doubt. I don't have to ask him, I know he'll be there ... and he'll decide the birth for a date that more or less suits him too." (Woman 11, fourth pregnancy)

*From audiotaped interviews with 21 pregnant women

\section{What is already known on this topic}

In 1997 Chile had the highest rate of caesarean sections $(40 \%)$ in Latin America

The rate in women with private health insurance in Chile is double that in women covered by the national health insurance fund

\section{What this study adds}

Patients' choice is unlikely to be the primary explanation for the high rate of caesarean sections in the private sector

Key factors contributing to the high rate include the requirement by private health insurers that an obstetrician, rather than a midwife, should be the primary care provider; women's expectations of personalised private care relationships; and the peripatetic work schedules of many obstetricians

of caesarean section than those in the public sector. This cannot be explained simply as a reflection of patients' choice in the private sector. Patients' choice is always a complex issue ${ }^{6-8}$ but there are few grounds for it being the sole explanation for Chile's high private sector rates of caesarean section.

Might the high rates in the private sector simply reflect a consensus in the obstetric establishment in Chile-a belief that caesarean section is now, because of advances in monitoring fetal wellbeing, the optimal method of delivery for many women? Statistics from one of Santiago's most exclusive hospitals, Clínica Las Condes, suggest not-indeed, they add validity to the time management thesis. Since 1991, the Clínica Las Condes has reported a steady decline in rates of caesarean section. ${ }^{9}$ By 1994 the rate among the women who were attended there by staff obstetricians was $28 \%$, well below the national average. Just over a fifth of the 1200 births were attended by visiting obstetricians, however, who work in several locations. Their caesarean section rate was twice as high, at $57 \%{ }^{9}$

To discourage high rates of caesarean section, insurance schemes in Chile had not, for five years before the study, paid obstetricians more for performing caesarean sections than for vaginal deliveries. In the private sector, some other aspects of the care package are also standard, irrespective of type of delivery. Anaesthetists routinely provide epidurals for both vaginal and caesarean deliveries. Paediatricians are present at all births. Elective caesarean can, however, facilitate the coordination of this team (and maximise their efficient use of time). Women normally stay in hospital for three days after the birth (whether vaginal or caesarean). Patients incur extra costs, however, as a result of surgery, and hospitals can be expected to benefit from these, as well as from the higher bed occupancy rates that result from programming.

Obstetricians do private work to increase their income. Conflicting demands arise from complex peripatetic work schedules and the need to provide personalised care for private patients. These are resolved by liberal use of caesarean section, which permits maximum efficiency in use of time. The prevailing business ethos in health care encourages 
such pragmatism among those doctors who do not have a moral objection to non-medical caesarean section.

Contributors: SFM is the sole author of this paper. She initiated the research, designed the protocol and the data collection instruments, conducted the in-depth interviews, coded and analysed the qualitative and quantitative data and wrote the paper Fanny Serani (lecturer at the University of Chile) participated in the piloting of the survey instrument and conducted the postnatal survey interviews. Mary Ann Elston (senior lecturer in the department of social and political science at Royal Holloway College, University of London) discussed core ideas and commented on an early draft of the paper. Angie Wade (senior lecturer, Institute of Child Health) provided statistical advice.

Funding: The study was supported by grant RD352 from the UK Department for International Development (DFID). The views expressed, however, are those of the author and do not represent the views of the DFID.

Competing interests: None declared.
1 Bélizan JM, Althabe F, Barros FC, Alexander S. Rates and implications of caesarean sections in Latin America: ecological study. $B M$ 1999;319:1397-400.

2 Murray SF, Serani Pradenas F. Cesarean birth trends in Chile 1986 to 1994. Birth 1997:24:258-63.

3 Miranda E, Scarpaci JL, Irarrázaval I. A decade of HMOs in Chile: market behaviour, consumer choice and the state. Health and Place 1995;1:51-9. Seale C. The quality of qualitative research. London: Sage, 1999;1-210.

5 Faúndes A, Cecatti JG. Which policy for caesarean sections in Brazil? An analysis of trends and consequences. Health Policy and Planning 1993;8:33-42.

6 Hopkins K. Are Brazilian women really choosing to deliver by cesarean? Soc Sci Med 2000;51:725-40.

7 Castro A. Commentary: increase in caesarean sections may reflect medical control not women's choice. BMJ 1997;319:1401-2.

8 De Mello, Souza C. C-sections as ideal births: the cultural constructions of beneficence and patients' rights in Brazil. Cambridge Quarterly of Healthcare Ethics 1994;3:358-66.

9 Schnapp C, Sepulveda W. Rise in caesarean births in Chile. Lancet 1997;349:1029.

(Accepted 28 September 2000)

\title{
Presence of relatives during testing for brain stem death: questionnaire study
}

\author{
Janet Pugh, Linda Clarke, Janine Gray, Jolien Haveman, Paul Lawler, Stephen Bonner
}

In brain stem death, where the body remains warm and pink and has a pulse and a chest that rises and falls, relatives may have difficulty accepting that the patient has for brain stem death being performed then this may improve their understanding that death has occurred. But, however careful the explanation, any potential benefit to relatives of observing testing for brain stem death may be offset by doubts caused by the movement of limbs during testing (due to spinal reflexes), which often occur when testing for cranial nerve activity (shown as facial movement) by using painful stimuli.

Despite these concerns, we occasionally allow relatives to observe testing for brain stem death because it may help some families to understand that the patient has died. As there is no evidence to support or refute this practice, we undertook a survey to establish current practice in intensive care units in the United Kingdom. died. It has been suggested that if relatives witness tests

\section{Subjects, methods, and results}

After obtaining ethical approval, we telephoned 28 neurotrauma intensive care units to identify which senior staff would usually be involved in testing for brain stem death. We sent a questionnaire to the 147 consultants and 167 senior nurses identified; the response rate was $79 \%(116 / 147)$ for consultants and $77 \%(129 / 167)$ for senior nurses.

Overall, $32 \%(37 / 116)$ of consultants and $42 \%$ (54/ 129) of nurses had experience of relatives' presence during testing, and $69 \%(63 / 91)$ of these felt that this was helpful for relatives (table). Nurses were more likely than doctors $(84 \% v 53 \%)$ to believe that witnessing the tests would help relatives to accept that the patient had died, and $48 \%$ thought that relatives may gain comfort from being present.

The major potential problems were cited as spinal reflexes $(85 \%)$ and dealing with the relatives' distress

Responses of consultants and senior nurses to questionnaire on the presence of relatives during testing for brain stem death*

\begin{tabular}{|c|c|c|}
\hline Item & $\begin{array}{l}\text { No }(\%) \text { of consultants } \\
\qquad(\mathrm{n}=116)\end{array}$ & $\begin{array}{l}\text { No }(\%) \text { of senior nurses } \\
(\mathrm{n}=129)\end{array}$ \\
\hline I have invited relatives to be present at testing for brain stem death & $22(19)$ & $29(23)$ \\
\hline I have been asked by relatives if they could attend testing for brain stem death & $35(30)$ & $54(42)$ \\
\hline I have allowed relatives to attend testing for brain stem death & $37(32)$ & $54(42)$ \\
\hline In my experience, attending testing helped the relatives & $23 / 37(63)$ & $40 / 54(74)$ \\
\hline The presence of relatives would affect my performance & $18(16)$ & $8(60)$ \\
\hline With appropriate support for relatives, I would be more willing to allow presence of relatives & $35(30)$ & $76(59)$ \\
\hline If the patient was a child it would make no difference to allowing relatives to be present & $81(70)$ & $79(61)$ \\
\hline \multicolumn{3}{|l|}{ Most frequently cited problems associated with the presence of relatives: } \\
\hline Spinal reflexes & $97(84)$ & $111(86)$ \\
\hline Handling relatives' distress & $84(72)$ & $88(68)$ \\
\hline Extra nurse needed for support & $54(47)$ & $47(36)$ \\
\hline Verbal interference from relatives & $35(30)$ & $47(36)$ \\
\hline \multicolumn{3}{|l|}{ Most frequently cited benefits associated with the presence of relatives: } \\
\hline Relatives more able to accept that patient has died & $61(53)$ & $108(84)$ \\
\hline Relatives gain comfort from being present & $52(45)$ & $65(50)$ \\
\hline
\end{tabular}

${ }^{*}$ Complete findings and questionnaire are available on the BMJ's website.
Intensive Care Unit, South Cleveland

Hospital,

Middlesbrough TS4 3BW

Janet Pugh nursing sister Linda Clarke nursing sister Paul Lawler consultant

Stephen Bonner consultant

Centre for Health and Medical Research, University of Teesside, Middlesbrough TS1 3BA

Janine Gray senior lecturer in medical statistics Jolien Haveman clinical psychologist

Correspondence to: $\mathrm{S}$ Bonner

BMJ 2000;321:1505-6

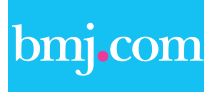

The questionnaires completed by the consultants and senior nurses appear on the $B M J$ 's website 